\title{
Application of intraoperative frozen section examination in the management of female breast cancer in China: a nationwide, multicenter 10-year epidemiological study
}

\author{
Ke Wang ${ }^{1 \dagger}$, Yu Ren ${ }^{1 \dagger}$, Rong Huang ${ }^{2,3}$, Jian-Jun He${ }^{1}$, Wei-Liang Feng ${ }^{4}$, Ya-Nan Kong ${ }^{5}$, Feng X ${ }^{6}$, Lin Zhao ${ }^{7}$, \\ Qing-Kun Song ${ }^{2}$, Jing Li ${ }^{2}$, Bao-Ning Zhang ${ }^{8}$, Jin-Hu Fan ${ }^{2}$, Xiao-Ming Xie ${ }^{5^{*}}$, Shan Zheng ${ }^{*^{*}}$ and You-Lin Qiao ${ }^{2}$
}

\begin{abstract}
Background: Intraoperative frozen section examination (IFSE) during breast cancer surgery can partly reflect the status of surgical treatment since the surgical method used directly determines the purpose of IFSE use in disease management. This study aims to investigate the application of, changing trends in, and factors influencing IFSE in the management of female breast cancer in China.

Methods: We collected the sociodemographic and clinical data of 4,211 breast cancer patients between 1999 and 2008 and statistically analyzed these data using $x^{2}$ or Fisher's exact tests.

Results: A total of 2,283 (54.22\%) patients with breast cancer underwent IFSE. During the 10-year study period, IFSE use was associated with an increase in the number of sentinel lymph node biopsies (SLNB) and breast-conserving surgeries (BS) performed, with significant regional differences noted in this trend $(P<0.05)$. Patients' education, occupation, age, tumor size estimated by preoperative palpation, and the use of imaging examinations affected the purpose of IFSE use $(P<0.05)$.

Conclusions: Our results show that the purpose of IFSE in the surgical treatment of breast cancer in China is gradually approaching that in developed countries. We believe that policymakers must address the differences in breast cancer treatment based on the socioeconomic status of patients. Lastly, the use of IFSE for determining tumor characteristics should be avoided as far as possible, and patient education and breast cancer screening programs tailored to the Chinese population should be established. Our findings may guide the formulation of breast cancer control strategies in China and other low-income countries.
\end{abstract}

Keywords: Application mode, Female breast cancer, Intraoperative frozen section examination, Sociodemographic factor

\section{Background}

Intraoperative frozen section examination (IFSE) was first performed by William $\mathrm{H}$. Welch in 1891. This method permits the rapid diagnosis of tumors during

\footnotetext{
*Correspondence: xxie1234@126.com; zhengshan1002@yahoo.com.cn ${ }^{\dagger}$ Equal contributors

${ }^{5}$ Department of Breast Oncology, Sun Yat-Sen University Cancer Center, 651 Dongfeng East, Guangzhou 510060, P.R. China

${ }^{9}$ Department of Pathology, Cancer Institute \& Hospital, Chinese Academy of Medical Sciences \& Peking Union Medical College, 17 South Panjiayuan Lane, Beijing 100021, P.R. China

Full list of author information is available at the end of the article
}

operation [1] and has become an indispensable part of surgical treatment of breast cancer, since it can guide operators in deciding the appropriate protocols during surgery [2]. Before the 1980s, IFSE was mostly used to determine the benignancy or malignancy of tumors intraoperatively [3]. Since 2000, with advances in tumor treatment methods as well as preoperative diagnostic methods, the use of IFSE has changed dramatically, especially in the case of breast cancer [4,5]. IFSE during breast cancer surgery can reflect, to a certain extent, the status of patients' surgical treatment, since the surgical

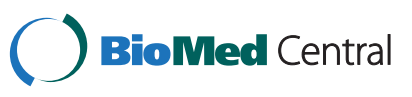


method used directly determines the purpose for which IFSE is used [6].

Although breast cancer is the most common cancer among women in China [7], few studies have analyzed the total population of breast cancer patients in the country. Our previous studies demonstrated, for the first time, the pathological characteristics of breast cancer in Chinese women $[8,9]$. The current study is part of a series of studies concerning the application and temporal tendencies of and regional differences in IFSE use in the diagnosis and treatment of female breast cancer in China during the period 1999-2008. We also examined factors affecting the purpose for which IFSE is used in breast cancer management.

\section{Methods}

\section{Subjects}

This series of studies was approved by the Institutional Review Board of the Cancer Foundation of China. The approval covered data collection from all the participating centers. Female patients with breast cancer who had received treatment (surgery, medical oncology, radiotherapy) were enrolled from seven first-class, grade III hospitals or referral centers in north, northeast, central, south, east, northwest, and southwest China [8]. Since there was no risk associated with participating in the study, patients' informed consent was not obtained. The identity of all patients was kept anonymous.

\section{Data collection}

According to the pre-designed recruitment protocol, at least 50 female patients with breast cancer were sampled from each hospital or referral center per year. The sampling method used could largely avoid selection bias. Two data input clerks from each site independently double-entered data from the patients' record into a computer database. Quality control was performed during each step of data collection. Finally, all completed double-entry databases were sent to the Cancer Hospital/Institute, Chinese Academy of Medical Sciences, for validation using the statistical software EpiData (http://www.epidata.dk/). Details of the methods have been described elsewhere [8].

Patient characteristics collected were general information, risk factors, imaging examination results, treatment mode, and clinicopathological characteristics of the tumors. Histological subtyping of tumors was based on the 1981 and 2003 WHO histological classification criteria $[10,11]$. Breast cancer staging was performed according to the American Joint Committee on Cancer tumor-node-metastasis staging system of 1997 and after $[12,13]$.

\section{Grouping criteria}

Subjects were assigned to two groups depending on the reason for using IFSE. In Group A, IFSE had been used for diagnosing the type of breast tumor, while in Group $\mathrm{B}$, it had been used to assess metastasis to a sentinel lymph node (SLN) and/or to identify the resection margin during breast-conserving surgery (BS) but not to identify the type of primary tumor.

The seven geographic regions mentioned were classified as high- or low-socioeconomic status (SES) areas, according to previously described criteria [14]. Four socioeconomic indicators were recorded: gross domestic product per capita, percentage of health-service expenditure in the regional/provincial public affairs general budget, ratio of urban to rural population, and percentage of illiteracy among females aged 15 and over. They were used to establish the SES of each area with the selected hospital or referral center.

According to the commonly used classification in China, the ages of the patients at diagnosis of breast cancer were divided into four groups: $<35$ years, 35-49 years, 50-64 years, and $>64$ years.

\section{Statistical analysis}

All statistical analyses were performed using the statistical software SPSS version 16.0 (SPSS Inc., Chicago, IL, USA). The trend $x^{2}$ test was employed to examine the temporal changes in IFSE application and its frequency during the period 1999 to 2008. Factors affecting the use of IFSE were analyzed using the $x^{2}$ test. The effect of preoperative examination methods on the frequency of IFSE use was evaluated using the $x^{2}$ test and Fisher's exact test. A $P$ value $<0.05$ was considered statistically significant.

\section{Results}

\section{Patient characteristics}

A total of 4,211 eligible breast cancer patients were enrolled in this series of studies, which comprised $9.3 \%$ of the total number of breast cancer cases encountered at the hospitals or referral centers [8]. Included in the 4,211 patients were 2,283 patients $(54.22 \%)$ who had undergone IFSE. In terms of age, 139 patients $(6.09 \%)$ were aged under 35 years at diagnosis, 1,145 (50.15\%) were aged between 35 and 49 years, 793 (34.73\%) between 50 and 64 years, and $206(9.02 \%)$ above 64 years. As mentioned, the seven geographic regions were grouped into low- and high-SES areas according to the area-based SES. High-SES areas were north, northeast, east, and south China, with 1,227 subjects (53.75\%); lowSES areas were northwest, central, and southwest China, with 1,056 subjects (46.25\%). 
Temporal changes in the use of IFSE

The total number and percentage of the patients who underwent IFSE during the 10-year study period did not change significantly year-on-year, as shown in Table 1. There was, however, a change in the reason for using IFSE (Table 2 and Figure 1). The number and percentages of IFSEs performed for identifying the type of primary tumor declined gradually, while the corresponding figures for assessment of metastasis to SLNs or identification of the resection margin increased gradually $(P$ $<0.05)$. Overall, during the study period, $94.61 \%(2,160 /$ $2,283)$ of IFSEs were used to identify the type of primary tumor, $2.98 \%(68 / 2,283)$ for sentinel lymph node biopsy (SLNB), and $9.46 \%(216 / 2,283)$ for BS. In most cases, IFSE was used exclusively for identifying the type of primary tumor $(2,014 / 2,283 ; 88.22 \%)$, whereas in $4.91 \%$ of cases $(112 / 2,283)$, it was performed to identify both the type of primary tumor and the resection margin for BS; fewer cases involved IFSE use exclusively for SLNB or identification of the resection margin for BS. Thus, IFSE for identifying the type of primary tumor (Group A) accounted for $94.61 \%$ of cases $(2160 / 2,283)$, while that for other reasons accounted for $5.39 \%$ of cases (123/ 2,283) (Group B; Table 2).

\section{Comparison of regional differences in the frequency of IFSE}

The frequency of IFSE use for various reasons differed among the different SES regions as well. In low-SES areas, the percentage of IFSE used for assessment of metastasis to SLNs and/or identification of the resection margin (Group B) was very low $(1.52 \% ; 16 / 1,056)$. In contrast, in high-SES areas it was significantly higher (8.72\%; 107/1,227; $P<0.05$ ) (Figure 2).

Table 1 Number and percentage of patients who underwent intraoperative frozen section examination (IFSE) between 1999 and 2008

\begin{tabular}{lccc}
\hline Year & IFSE (\%) & No IFSE or unknown (\%) & Total \\
\hline 1999 & $210(52.11)$ & $193(47.89)$ & 403 \\
2000 & $169(48.29)$ & $181(51.71)$ & 350 \\
2001 & $199(52.79)$ & $178(47.21)$ & 377 \\
2002 & $178(52.20)$ & $163(47.80)$ & 341 \\
2003 & $238(61.03)$ & $152(38.97)$ & 390 \\
2004 & $241(57.79)$ & $176(42.21)$ & 417 \\
2005 & $202(49.75)$ & $204(50.25)$ & 406 \\
2006 & $259(56.06)$ & $203(43.94)$ & 462 \\
2007 & $334(58.80)$ & $234(41.20)$ & 568 \\
2008 & $253(50.91)$ & $244(49.09)$ & 497 \\
Total & $2,283(54.22)$ & $1,928(45.78)$ & 4,211 \\
\hline
\end{tabular}

Table 2 Frequency of intraoperative frozen section examination (IFSE) use between 1999 and 2008

\begin{tabular}{lccc}
\hline Year & Group A (\%) & Group B (\%) & Total \\
\hline 1999 & $209(99.52)$ & $1(0.48)$ & 210 \\
2000 & $165(97.63)$ & $4(2.37)$ & 169 \\
2001 & $198(99.50)$ & $1(0.50)$ & 199 \\
2002 & $176(98.88)$ & $2(1.12)$ & 178 \\
2003 & $228(95.80)$ & $10(4.20)$ & 238 \\
2004 & $227(94.19)$ & $14(5.81)$ & 241 \\
2005 & $184(91.09)$ & $18(8.91)$ & 202 \\
2006 & $240(92.66)$ & $19(7.34)$ & 259 \\
2007 & $307(91.92)$ & $27(8.08)$ & 334 \\
2008 & $226(89.33)$ & $27(10.67)$ & 253 \\
Total & $2,160(94.61)$ & $123(5.39)$ & 2,283 \\
\hline
\end{tabular}

Group A: IFSE had been used for diagnosing the type of breast tumor. Group B: IFSE had been used to assess metastasis to a SLN and/or to identify the resection margin during BS but not to identify the type of primary tumor.

\section{Effect of sociodemographic characteristics on the frequency of IFSE use}

Table 3 shows the effects of patients' sociodemographic characteristics on indications for IFSE. Most patients who underwent IFSE were educated up to junior and senior high school $(48.96 \% ; 638 / 1,303)$, and the main occupation was manual work, accounting for $51.07 \%$ $(1,024 / 2,005)$ of the total patient population. A little more than half the study population was in the 35 to 49 years age range $(50.15 \% ; 1,145 / 2,283)$. Statistical analyses showed that the level of education, occupation, and age all affected the indications for IFSE, as follows: i) Group A gradually reduced with advanced education level, while Group B increased significantly $(P=0.001)$. ii) The purpose of IFSE use also varied according to patients' occupations. The highest percentage of Group A

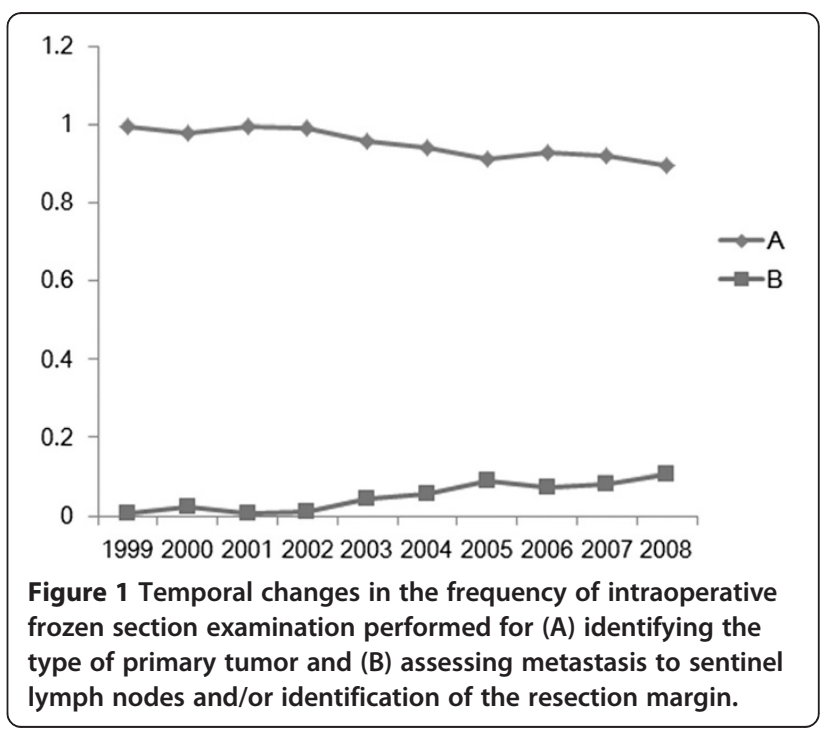




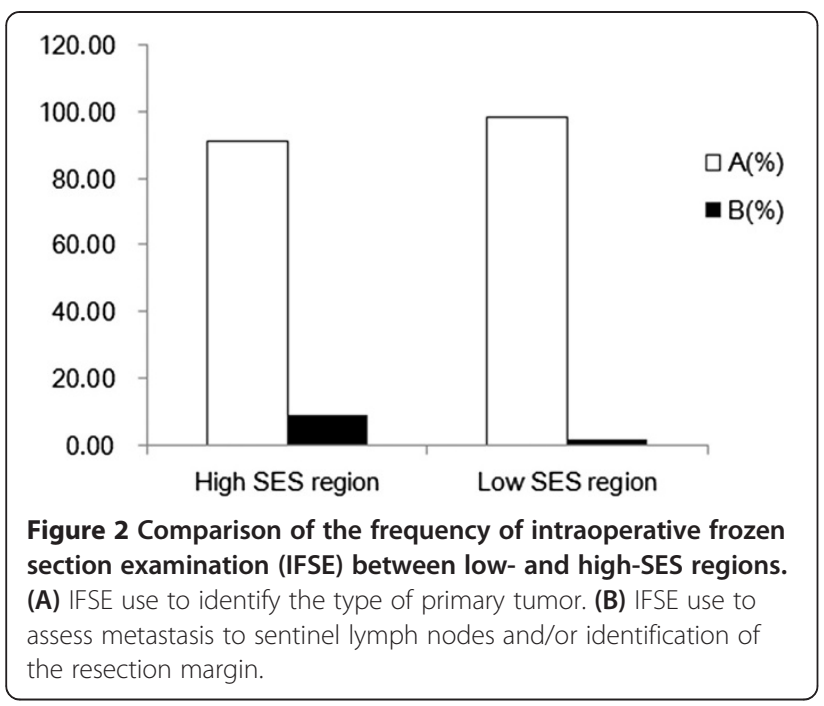

(96.09\%) was observed among manual workers, while the highest percentage of Group B (8.37\%) was found among intellectual workers, and the between-group difference was significant $(P<0.001)$. iii) Lastly, Group A showed a gradually increasing tendency with age, while Group B exhibited a gradually declining tendency with age $(P<0.001)$.

\section{Effects of preoperative examinations on purpose of IFSE} use

The effects of preoperative examinations on the indications for IFSE are shown in Table 4. Both the tumor size, determined by preoperative palpation, and the performance of molybdenum-target X-ray or ultrasonography examinations prior to surgery affected the purpose of
IFSE use $(P<0.05)$. IFSE was performed in a higher percentage for Group B purpose in patients who had tumor sizes $\leq 20 \mathrm{~mm}$ or who had undergone molybdenumtarget X-ray or ultrasonography examinations $(P<0.05)$; on the contrary, the percentage of Group A was significantly lower in these patients $(P<0.05)$. The lymph node status, determined by preoperative palpation, was not significantly correlated with the purpose of IFSE use ( $P$ $>0.05)$.

\section{Discussion}

With continual advances in science and technology and evolution of breast cancer treatment, IFSE plays an increasingly important role in the surgical treatment of this disease. Simultaneously, the principal purpose of IFSE has shifted from identification of tumor type to identification of SLN metastasis and assessment of the resection margin during $B S$. In our previous nationwide multicenter retrospective clinical epidemiological studies of female breast cancer in China, we described the pathological characteristics of this condition $[8,9]$. The present study, which is part of a series of studies, investigated the application of IFSE and factors that influence its use in the management of female breast cancer. An objective of this study was to guide the formulation of breast cancer control strategies in China and other lowincome countries.

First, we analyzed the indications for IFSE and changing trends in its use. The results showed that IFSE was still mainly used to identify the type of breast tumor. However, its overall use for this purpose has declined over the 10-year study period, while its use for assessment of metastasis to SLNs and identification of the

Table 3 Effect of patients' sociodemographic characteristics on the frequency of IFSE use

\begin{tabular}{|c|c|c|c|c|c|c|c|c|}
\hline \multicolumn{2}{|c|}{ Sociodemographic characteristic } & \multicolumn{2}{|c|}{ Group A } & \multicolumn{2}{|c|}{ Group B } & \multirow[t]{2}{*}{ Total } & \multirow{2}{*}{$\begin{array}{c}\mathrm{X}^{2} \\
\text { value }\end{array}$} & \multirow{2}{*}{$\begin{array}{c}P \\
\text { value }\end{array}$} \\
\hline & & Number & Percentage (\%) & Number & Percentage (\%) & & & \\
\hline \multirow[t]{3}{*}{ Education level } & Primary school and lower & 372 & 98.41 & 6 & 1.59 & 378 & & \\
\hline & Junior and senior high school & 626 & 98.12 & 12 & 1.88 & 638 & 14.835 & 0.001 \\
\hline & Junior college and higher & 270 & 94.08 & 17 & 5.92 & 287 & & \\
\hline Total & & 1,268 & & 35 & & $1,303^{*}$ & & \\
\hline \multirow[t]{3}{*}{ Occupation } & Manual work & 984 & 96.09 & 40 & 3.91 & 1,024 & & \\
\hline & Intellectual work & 569 & 91.63 & 52 & 8.37 & 621 & 15.902 & $<0.001$ \\
\hline & Other** & 344 & 95.56 & 16 & 4.44 & 360 & & \\
\hline Total & & 1,897 & & 108 & & $2,005^{*}$ & & \\
\hline \multirow[t]{4}{*}{ Age (years) } & $<35$ & 114 & 82.01 & 25 & 17.99 & 139 & 59.602 & $<0.001$ \\
\hline & $35-49$ & 1,074 & 93.80 & 71 & 6.20 & 1,145 & & \\
\hline & $50-64$ & 774 & 97.60 & 19 & 2.40 & 793 & & \\
\hline & $>64$ & 198 & 96.12 & 8 & 3.88 & 206 & & \\
\hline Total & & 2,160 & & 123 & & 2,283 & & \\
\hline
\end{tabular}

* Patients whose data were unavailable are not included in the table. ** Other: Those with occupations that are difficult to classify as manual or intellectual work, namely, housewives, merchants, soldiers, and unemployed individuals. 
Table 4 Effects of preoperative examinations on the frequency of intraoperative frozen section examination use

\begin{tabular}{|c|c|c|c|c|c|c|c|c|c|}
\hline \multirow[t]{2}{*}{ Preoperative examination items } & & \multicolumn{2}{|c|}{ Group A } & \multicolumn{2}{|c|}{ Group B } & \multirow[t]{2}{*}{ Total } & \multirow{2}{*}{$\begin{array}{c}x^{2} \\
\text { value }\end{array}$} & \multirow{2}{*}{$\begin{array}{c}P \\
\text { value }\end{array}$} & \multirow{2}{*}{$\begin{array}{c}\text { Fisher's } \\
\text { exact } \\
\text { probability }\end{array}$} \\
\hline & & Number & $\begin{array}{l}\text { Percentage } \\
(\%)\end{array}$ & Number & $\begin{array}{l}\text { Percentage } \\
(\%)\end{array}$ & & & & \\
\hline \multirow[t]{2}{*}{ Tumor size estimated by palpation } & $\leq 20 \mathrm{~mm}$ & 752 & 93.07 & 56 & 6.93 & 808 & 5.842 & 0.016 & - \\
\hline & $>20 \mathrm{~mm}$ & 1,408 & 95.46 & 67 & 4.54 & 1,475 & & & \\
\hline Total & & 2,160 & & 123 & & 2,283 & & & \\
\hline \multirow[t]{2}{*}{$\begin{array}{l}\text { Lymph node status determined by } \\
\text { palpation }\end{array}$} & $\begin{array}{l}\text { No metastasis } \\
\text { (NO) }\end{array}$ & 1,470 & 95.08 & 76 & 4.92 & 1,546 & 0.315 & 0.575 & - \\
\hline & $\begin{array}{l}\text { Metastasis } \\
(\mathrm{N} 1-3)\end{array}$ & 566 & 94.49 & 33 & 5.51 & 599 & & & \\
\hline Total & & 2,036 & & 109 & & $2,145^{*}$ & & & \\
\hline \multirow[t]{2}{*}{ Molybdenum-target X-ray } & Not used & 1,368 & 96.75 & 46 & 3.25 & 1,414 & 12.333 & $<0.001$ & - \\
\hline & Used & 655 & 93.44 & 46 & 6.56 & 701 & & & \\
\hline Total & & 2,023 & & 92 & & $2,115^{*}$ & & & \\
\hline \multirow[t]{2}{*}{ Ultrasonography } & Not used & 612 & 97.45 & 16 & 2.55 & 628 & 6.832 & 0.009 & - \\
\hline & Used & 1,421 & 94.92 & 76 & 5.08 & 1,497 & & & \\
\hline Total & & 2,033 & & 92 & & $2,125^{*}$ & & & \\
\hline \multirow[t]{2}{*}{ MRI } & Not used & 2,083 & 95.16 & 106 & 4.84 & 2,189 & - & - & 0.088 \\
\hline & Used & 65 & 90.28 & 7 & 9.72 & 72 & & & \\
\hline Total & & 2,148 & & 113 & & $2,261^{*}$ & & & \\
\hline
\end{tabular}

* Patients whose data were not available are not included in the table.

resection margin for BS has gradually increased. The indications for IFSE in China differ from those in developed countries, where SLNB and BS are the major indications for surgical treatment of breast cancer [15-27]. Correspondingly, the purpose of IFSE use has changed. IFSE is increasingly being applied in SLNB and $\mathrm{BS}$ and less so for identifying the type of primary tumor [15]. Both the Edge report from the $28^{\text {th }}$ Annual San Antonio Breast Cancer Symposium [28] and the results of the NSABP B-32 clinical trial [29] indicated that open surgical resection combined with IFSE is no longer an acceptable treatment for breast cancer in developed countries. However, differences in economic levels may necessitate differences in treatment modes for breast cancer across countries [30-32]. The overall level of economic development is significantly lower in China than in developed countries, and this could affect diseasecontrol strategies. In the present area-stratified analysis, we found that regional differences in economic development affected the use of IFSE: regions with high-SES tended to use IFSE for assessment of metastasis to SLNs and identifying the resection margin during BS more frequently than those with low-SES. We believe that in developing countries or regions, the use of preoperative biopsy techniques should be increased in order to decrease the use of IFSE for intraoperative diagnosis of breast tumor so that we can choose the more appropriate treatment pattern before operation. Our results are encouraging in that we found that the use of IFSE for
SLNB and BS has significantly increased over the 10year study period, while its use for identifying the type of primary tumor has decreased. This trend suggests that surgical treatment of breast cancer in China is gradually approaching that of developed countries. We believe that the influence of regional differences in economic levels on the use of IFSE and breast cancer control strategies deserves more attention as a means of benefiting more patients.

We also evaluated the effects of patients' sociodemographic characteristics on the use of IFSE for surgical treatment of breast cancer. We found that the purpose of IFSE use was closely associated with patients' education, occupation, and age. This association may be attributed to the following factors: i) The time to diagnosis is longer in the case of patients of lower educational level, lower occupational income, and older age [33-35], because of which they have advanced disease and the opportunity to perform SLNB and BS is poor. ii) Subjects with higher educational levels and income are more willing to accept new concepts and technologies, such as SLNB and BS [36,37]. iii) Subjects with lower incomes cannot afford post-surgical radiotherapy, and most live in poor areas where radiotherapy is seldom performed [37]. iv) Younger patients are more likely to care about the esthetics of surgery and hence may be more willing to accept BS and SLNB [38,39], while older patients are more prone to reject these two types of surgery [40]. On the basis of these findings, we believe that better 
education among individuals of low-SES should be emphasized in order to help them accept SLNB and BS.

Finally, we assessed the effects of preoperative examinations on the purpose of IFSE use. Our previous study showed that imaging examinations affected the clinicopathological characterization of breast cancer at diagnosis [9]. The current study found that the frequency of imaging examinations also affected the rate of IFSE use. Greater implementation of imaging examinations led to greater use of IFSE for SLNB and BS. The following reasons may explain this phenomenon: i) Breast cancer can be detected at earlier stages in patients who have undergone molybdenum-target X-ray and ultrasonographic examinations; therefore, their tumors may be smaller and the possibility of SLN metastasis is lower $[41,42]$, and, consequently, these patients are more likely to receive SLNB and BS. ii) Second, preoperative molybdenum-target X-ray and ultrasonographic examinations can better predict the safety of SLNB and BS [43-45]. In the present study, we also found that tumor size, as estimated by preoperative palpation, affected the indications for IFSE, in that IFSE was used more frequently for SLNB and BS in patients with tumors $\leq 20 \mathrm{~mm}$. This finding may demonstrate that preoperative estimation of tumor size is a key factor in determining whether BS will be performed [46,47], as BS is safest when tumors are small [48]. Conversely, patients with large tumors have a higher probability of having axillary lymph node metastasis $[49,50]$ and a greater risk of complications from a SLNB $[51,52]$.

Our study has a limitation, which must be acknowledged: since subjects were enrolled from hospitals or referral centers in seven traditional geographic regions, a selection bias may have been present. In China, most patients with breast cancer visit high-grade hospitals. All hospitals or referral centers involved in the present study are grade III and have the requisite physician resources and equipment for performing IFSE. However, grade I and II hospitals lack the resources to perform comprehensive breast cancer therapy, including IFSE. Nonetheless, since our study had a broad base and included diverse populations, the selection method used is probably the most suitable to reflect the diverse nature of present-day China.

\section{Conclusions}

In summary, in the present study, we analyzed the use of IFSE in the diagnosis and treatment of breast cancer in China during the 10-year period from 1999 to 2008. From our observations, we concluded that IFSE is still used mainly to identify the type of breast tumor. Ideally, the use of preoperative biopsy techniques should be improved so that IFSE use for tumor diagnosis during breast cancer operations can be decreased. In line with the introduction of newer concepts in breast cancer treatment and treatment modes, the purpose of IFSE in surgical treatment of breast cancer in China is gradually approaching that of developed countries. Nevertheless, regional differences in IFSE use require the attention of policymakers. Finally, patients' sociodemographic characteristics and the availability and use of preoperative imaging examinations significantly affect the use of IFSE in breast cancer treatment. Therefore, better education and breast cancer screening suitable for China's needs may help prevent breast cancer and aid the system in serving those with this disease.

\section{Abbreviations}

BS: Breast-conserving surgery; IFSE: Intraoperative frozen section examination; SLNB: Sentinel lymph node biopsy; SLN: Sentinel lymph node;

SES: Socioeconomic status.

\section{Competing interests}

The authors declare that they have no competing interests.

\section{Authors' contributions}

KW and YR helped to analyze and interpret the data and drafted the initial manuscript. RH, JJH, YR, and WLF helped to design the study. WLF, YNK, FX, LZ, and QKS helped with local data collection. JL, BNZ, and JHF helped with the data management and analysis. XMX and SZ did critical revisions of the manuscript. All authors read and approved the final manuscript.

\section{Acknowledgments}

We thank Cancer Foundation of China for originating this retrospective clinical epidemiological study of breast cancer. We thank the local investigators from Beijing, Liaoning (Shenyang), Hunan (Changsha), Guangdong (Guangzhou), Zhejiang (Hangzhou), Shanxi (Xi'an), and Sichuan (Chengdu) for data collection and assisting us in the successful completion of the project. The authors also thank Pfizer for funding in the form of donations to Cancer Foundation of China.

\section{Author details}

'Department of Oncosurgery, the First Affiliated Hospital of Medical College, Xi'an Jiaotong Universtiy, 277 Yanta West Road, Xi'an 710061, P.R. China. ${ }^{2}$ Department of Cancer Epidemiology, Cancer Institute \& Hospital, Chinese Academy of Medical Sciences \& Peking Union Medical College, 17 South Panjiayuan Lane, Beijing 100021, P.R. China. ${ }^{3}$ Department of Epidemiology, West China School of Public Health, Sichuan University, Chengdu, Sichuan 610041, P.R. China. ${ }^{4}$ Department of Breast Surgery, Zhejiang Cancer Hospital, No. 38 Banshanqiao Guanji Road, Hangzhou 310022, P.R. China. ${ }^{5}$ Department of Breast Oncology, Sun Yat-Sen University Cancer Center, 651 Dongfeng East, Guangzhou 510060, P.R. China. 'Department of Breast-thyroid Surgery, Xiangya Second Hospital, Central South University, No. 139 Renminzhonglu, Changsha 410011, P.R. China. ${ }^{7}$ Department of Breast Surgery, Liaoning Cancer Hospital, No. 44 Xiaoyanhe Road, Dadong District, Shenyang 110041, P.R. China. ${ }^{8}$ Center of Breast Disease, Cancer Institute \& Hospital, Chinese Academy of Medical Sciences \& Peking Union Medical College, 17 South Panjiayuan Lane, Beijing 100021, P.R. China. 'Department of Pathology, Cancer Institute \& Hospital, Chinese Academy of Medical Sciences \& Peking Union Medical College, 17 South Panjiayuan Lane, Beijing 100021, P.R. China.

Received: 16 November 2013 Accepted: 4 July 2014

Published: 18 July 2014

\section{References}

1. Sparkman RS: Reliability of frozen sections in the diagnosis of breast lesions. Ann Surg 1962, 155:924-934.

2. Bloodgood JC: When cancer becomes a microscopic disease, there must be tissue diagnosis in the operating room. JAMA 1927, 88(13):1022-1023.

3. Dankwa EK, Davies JD: Frozen section diagnosis: an audit. J Clin Pathol 1985, 38(11):1235-1240. 
4. Laucirica R: Intraoperative assessment of the breast: guidelines and potential pitfalls. Arch Pathol Lab Med 2005, 129(12):1565-1574.

5. Ghaemmaghami F, Behnamfar F, Ensani F: Intraoperative frozen sections for assessment of female cancers. Asian Pac J Cancer Prev 2007, 8(4):635-639.

6. Jaafar $\mathrm{H}$ : Intra-operative frozen section consultation: concepts, applications and limitations. Malays J Med Sci 2006, 13(1):4-12.

7. Yang L, Parkin DM, Ferlay J, Li L, Chen Y: Estimates of cancer incidence in China for 2000 and projections for 2005. Cancer Epidemiol Biomarkers Prev 2005, 14(1):243-250.

8. Li J, Zhang BN, Fan JH, Pang Y, Zhang P, Wang SL, Zheng S, Zhang B, Yang HJ, Xie XM, Tang ZH, Li H, Li JY, He JJ, Qiao YL: A nation-wide multicenter 10-year (1999-2008) retrospective clinical epidemiological study of female breast cancer in China. BMC Cancer 2011, 11:364.

9. Zheng S, Bai JQ, Li J, Fan JH, Pang Y, Song QK, Huang R, Yang HJ, Xu F, Lu N, Qiao YL: The pathologic characteristics of breast cancer in China and its shift during 1999-2008: a national-wide multicenter cross-sectional image over 10 years. Int J Cancer 2012, 131(11):2622-2631.

10. Scarff RW, Torloni H: Histological Typing of Breast Tumours. 2nd edition. Geneva: World Health Organization; 1981:15-26.

11. Tavassoli FA, Devilee P: Pathology and Genetics of Tumours of the Breast and Female Genital Organs, Volume 4. Lyon: IARC, World Health Organization; 2003:221-232.

12. American Joint Committee on Cancer: AJCC cancer staging manual. 5th edition. Philadelphia: Lippincott-Raven; 1997:171-180.

13. American Joint Committee on Cancer: AJCC cancer staging manual. 6th edition. New York: Springer; 2002:223-240.

14. Wang Q, Li J, Zheng S, Li JY, Pang Y, Huang R, Zhang BN, Zhang B, Yang HJ, Xie XM, Tang ZH, Li H, He JJ, Fan JH, Qiao YL: Breast cancer stage at diagnosis and area-based socioeconomic status: a multicenter 10-year retrospective clinical epidemiological study in China. BMC Cancer 2012, $12: 122$.

15. Leong SP, Shen ZZ, Liu TJ, Agarwal G, Tajima T, Paik NS, Sandelin K, Derossis A, Cody H, Foulkes WD: Is breast cancer the same disease in Asian and Western countries? World J Surg 2010, 34(10):2308-2324

16. Giuliano AE: Sentinel node biopsy: standard of care. Breast J 2003, 9(s1): S3-S6.

17. Edge SB, Niland JC, Bookman MA, Theriault RL, Ottesen R, Lepisto E, Weeks $J C$ : Emergence of sentinel node biopsy in breast cancer as standard-ofcare in academic comprehensive cancer centers. J Natl Cancer Inst 2003, 95(20):1514-1521.

18. Goyal A, Mansel RE: Recent advances in sentinel lymph node biopsy for breast cancer. Curr Opin Oncol 2008, 20(6):621-626.

19. Burak WE Jr, Agnese DM, Povoski SP: Advances in the surgical management of early stage invasive breast cancer. Curr Prob/ Surg 2004, 41(11):882-935.

20. Povoski SP, Jimenez RE, Wang WP, Xu RX: Standardized and reproducible methodology for the comprehensive and systematic assessment of surgical resection margins during breast-conserving surgery for invasive breast cancer. BMC Cancer 2009, 9:254.

21. Zhang $B N$ : Progress in surgical treatment of early stage breast cancer. J Practical Oncol 2002, 17(6):367-369.

22. Fisher B, Anderson S, Bryant J, Margolese RG, Deutsch M, Fisher ER, Jeong $\mathrm{JH}$, Wolmark N: Twenty-year follow-up of a randomized trial comparing total mastectomy, lumpectomy, and lumpectomy plus irradiation for the treatment of invasive breast cancer. N Engl J Med 2002, 347(16):1233-1241.

23. Blichert-Toft M, Nielsen M, During M, Moller S, Rank F, Overgaard M, Mouridsen $\mathrm{HT}$ : Long-term results of breast conserving surgery vs. mastectomy for early stage invasive breast cancer: 20-year follow-up of the Danish randomized DBCG-82TM protocol. Acta Oncol 2008, 47(4):672-681

24. Fleissig A, Fallowfield LJ, Langridge Cl, Johnson L, Newcombe RG, Dixon JM, Kissin M, Mansel RE: Post-operative arm morbidity and quality of life. Results of the ALMANAC randomised trial comparing sentinel node biopsy with standard axillary treatment in the management of patients with early breast cancer. Breast Cancer Res Treat 2006, 95(3):279-293.

25. Veronesi U, Paganelli G, Viale G, Luini A, Zurrida S, Galimberti V, Intra M, Veronesi P, Robertson C, Maisonneuve P, Renne G, De Cicco C, De Lucia F, Gennari R: A randomized comparison of sentinel-node biopsy with routine axillary dissection in breast cancer. N Engl J Med 2003, 349(6):546-553.
26. Julian TB, Krag D, Brown A, Anderson S, Harlow S, Ashikaga T, Weaver D, Miller B, Jalovec L, Frazier T: Preliminary technical results of NSABP B-32, a randomized phase III clinical trial to compare sentinel node resection to conventional axillary dissection in clinically node-negative breast cancer patients. Breast Cancer Res Treat 2004, 88(Suppl 1):S11-S12.

27. Gnant M, Harbeck N, Thomssen C: St. Gallen 2011: Summary of the Consensus Discussion. Breast Care (Basel) 2011, 6(2):136-141.

28. Edge SB, Ottesen RA, Lepisto EM, Niland JC, Theriault RL, Bookman MA, Weeks JC: Surgical biopsy to diagnose breast cancer adversely affects outcomes of breast cancer care: finding from the National Comprehensive Cancer Network. Breast Cancer Res Treatmen 2005, 94(Suppl 1):S9. Abstract \#12.

29. Krag DN, Anderson SJ, Julian TB, Brown AM, Harlow SP, Ashikaga T, Weaver DL, Miller BJ, Jalovec LM, Frazier TG, Noyes RD, Robidoux A, Scarth HM, Mammolito DM, McCready DR, Mamounas EP, Costantino JP, Wolmark N, National Surgical Adjuvant Breast and Bowel Project: Technical outcomes of sentinel-lymph-node resection and conventional axillary-lymph-node dissection in patients with clinically node-negative breast cancer: results from the NSABP B-32 randomised phase III trial. Lancet Oncol 2007, 8(10):881-888.

30. Smith GL, Xu Y, Shih YC, Giordano SH, Smith BD, Hunt KK, Strom EA, Perkins $\mathrm{GH}$, Hortobagyi GN, Buchholz TA: Breast-conserving surgery in older patients with invasive breast cancer: current patterns of treatment across the United States. J Am Coll Surg 2009, 209(4):425-433.

31. Farrow DC, Hunt WC, Samet JM: Geographic variation in the treatment of localized breast cancer. N Engl J Med 1992, 326(17):1097-1101.

32. Nattinger AB, Gottlieb MS, Veum J, Yahnke D, Goodwin JS: Geographic variation in the use of breast-conserving treatment for breast cancer. N Engl J Med 1992, 326(17):1102-1107.

33. Richardson JL, Langholz B, Bernstein L, Burciaga C, Danley K, Ross RK: Stage and delay in breast cancer diagnosis by race, socioeconomic status, age and year. Br J Cancer 1992, 65(6):922-926.

34. Bish A, Ramirez A, Burgess C, Hunter M: Understanding why women delay in seeking help for breast cancer symptoms. J Psychosom Res 2005, 58(4):321-326.

35. Grunfeld EA, Ramirez AJ, Hunter MS, Richards MA: Women's knowledge and beliefs regarding breast cancer. Br J Cancer 2002, 86(9):1373-1378.

36. Keating NL, Weeks JC, Borbas C, Guadagnoli E: Treatment of early stage breast cancer: do surgeons and patients agree regarding whether treatment alternatives were discussed? Breast Cancer Res Treat 2003, 79(2):225-231.

37. Gilligan MA, Kneusel RT, Hoffmann RG, Greer AL, Nattinger AB: Persistent differences in sociodemographic determinants of breast conserving treatment despite overall increased adoption. Med Care 2002, 40(3):181-189.

38. Mandelblatt JS, Hadley J, Kerner JF, Schulman KA, Gold K, Dunmore-Griffith J, Edge S, Guadagnoli E, Lynch JJ, Meropol NJ, Weeks JC, Winn R: Patterns of breast carcinoma treatment in older women: patient preference and clinical and physical influences. Cancer 2000, 89(3):561-573.

39. Morrow M, White J, Moughan J, Owen J, Pajack T, Sylvester J, Wilson JF, Winchester D: Factors predicting the use of breast-conserving therapy in stage I and II breast carcinoma. J Clin Oncol 2001, 19(8):2254-2262.

40. Kowdley GC, Merchant N, Richardson JP: Cancer surgery in the elderly. Scientific World J 2012, 2012:303852.

41. Medina-Franco H, Abarca-Perez L, Garcia-Alvarez MN, Ulloa-Gomez JL, Romero-Trejo C, Sepulveda-Mendez J: Radioguided occult lesion localization (ROLL) versus wire-guided lumpectomy for non-palpable breast lesions: a randomized prospective evaluation. J Surg Oncol 2008, 97(2):108-111.

42. Singletary SE: Surgical margins in patients with early-stage breast cancer treated with breast conservation therapy. Am J Surg 2002, 184(5):383-393.

43. Krekel NM, Zonderhuis BM, Schreurs HW, Cardozo AM, Rijna H, van der Veen H, Muller S, Poortman P, de Widt L, de Roos WK, Bosch AM, Taets van Amerongen $\mathrm{AH}$, Bergers $\mathrm{E}$, van der Linden $\mathrm{MH}$, de Lange de Klerk ES, Winters HA, Meijer S, van den Tol PM: Ultrasound-guided breast-sparing surgery to improve cosmetic outcomes and quality of life. A prospective multicentre randomised controlled clinical trial comparing ultrasoundguided surgery to traditional palpation-guided surgery (COBALT trial). BMC Surg 2011, 11:8.

44. Pleijhuis RG, Graafland M, de Vries J, Bart J, de Jong JS, van Dam GM: Obtaining adequate surgical margins in breast-conserving therapy for 
patients with early-stage breast cancer: current modalities and future directions. Ann Surg Oncol 2009, 16(10):2717-2730.

45. Yang JD, Lee JW, Kim WW, Jung JH, Park HY: Oncoplastic surgical techniques for personalized breast conserving surgery in breast cancer patient with small to moderate sized breast. J Breast Cancer 2011, 14(4):253-261.

46. Veronesi U, Cascinelli N, Mariani L, Greco M, Saccozzi R, Luini A, Aguilar M, Marubini E: Twenty-year follow-up of a randomized study comparing breast-conserving surgery with radical mastectomy for early breast cancer. N Engl J Med 2002, 347(16):1227-1232.

47. Jeevan R, Cromwell DA, Trivella M, Lawrence G, Kearins O, Pereira J, Sheppard C, Caddy CM, van der Meulen JH: Reoperation rates after breast conserving surgery for breast cancer among women in England: retrospective study of hospital episode statistics. BMJ 2012, 345:e4505.

48. Schwartz GF, Veronesi U, Clough KB, Dixon JM, Fentiman IS, HeywangKobrunner SH, Holland R, Hughes KS, Mansel RE, Margolese R, Mendelson EB, Olivotto IA, Palazzo JP, Solin L, Consensus Conference Committee: Consensus conference on breast conservation. J Am Coll Surg 2006, 203(2):198-207.

49. Silverstein MJ, Skinner KA, Lomis TJ: Predicting axillary nodal positivity in 2282 patients with breast carcinoma. World J Surg 2001, 25(6):767-772.

50. Fein DA, Fowble BL, Hanlon AL, Hooks MA, Hoffman JP, Sigurdson ER, Jardines LA, Eisenberg BL: Identification of women with T1-T2 breast cancer at low risk of positive axillary nodes. J Surg Oncol 1997, 65(1):34-39.

51. Mansel RE, Fallowfield L, Kissin M, Goyal A, Newcombe RG, Dixon JM, Yiangou C, Horgan K, Bundred N, Monypenny I, England D, Sibbering M, Abdullah TI, Barr L, Chetty U, Sinnett DH, Fleissig A, Clarke D, Ell PJ: Randomized multicenter trial of sentinel node biopsy versus standard axillary treatment in operable breast cancer: the ALMANAC Trial. J Natl Cancer Inst 2006, 98(9):599-609.

52. Noguchi M, Motomura K, Imoto S, Miyauchi M, Sato K, Iwata H, Ohta M, Kurosumi M, Tsugawa K: A multicenter validation study of sentinel lymph node biopsy by the Japanese Breast Cancer Society. Breast Cancer Res Treat 2000, 63(1):31-40.

doi:10.1186/1477-7819-12-225

Cite this article as: Wang et al:: Application of intraoperative frozen section examination in the management of female breast cancer in China: a nationwide, multicenter 10 -year epidemiological study. World Journal of Surgical Oncology 2014 12:225.

\section{Submit your next manuscript to BioMed Central and take full advantage of:}

- Convenient online submission

- Thorough peer review

- No space constraints or color figure charges

- Immediate publication on acceptance

- Inclusion in PubMed, CAS, Scopus and Google Scholar

- Research which is freely available for redistribution 